\title{
Biomechanical drawbacks of different techniques of mitral neochordal implantation: When an apparently optimal repair can fail
}

\author{
Francesco Sturla, $\mathrm{PhD},{ }^{\mathrm{a}, \mathrm{b}}$ Emiliano Votta, $\mathrm{PhD},{ }^{\mathrm{b}}$ Francesco Onorati, MD, PhD, ${ }^{\mathrm{a}}$ \\ Konstantinos Pechlivanidis, MD, ${ }^{\mathrm{a}}$ Omar A. Pappalardo, MSc, ${ }^{\mathrm{a}, \mathrm{b}}$ Leonardo Gottin, MD, \\ Aldo D. Milano, MD, ${ }^{\mathrm{a}}$ Giovanni Puppini, $\mathrm{MD},{ }^{\mathrm{d}}$ Alberto Redaelli, $\mathrm{PhD},{ }^{\mathrm{b}}$ and Giuseppe Faggian, $\mathrm{MD}^{\mathrm{a}}$
}

\begin{abstract}
Objectives: Intraoperative assessment of the proper neochordal length during mitral plasty may be complex sometimes. Patient-specific finite element models were used to elucidate the biomechanical drawbacks underlying an apparently correct mitral repair for isolated posterior prolapse.

Methods: Preoperative patient-specific models were derived from cardiac magnetic resonance images; integrated with intraoperative surgical details to assess the location and extent of the prolapsing region, including the number and type of diseased chordae; and complemented by the biomechanical properties of mitral leaflets, chordae tendineae, and artificial neochordae. We investigated postoperative mitral valve biomechanics in a wide spectrum of different techniques (single neochorda, double neochordae, and preconfigured neochordal loop), all reestablishing adequate valvular competence, but differing in suboptimal millimetric expanded polytetrafluoroethylene suture lengths in a range of $\pm 2 \mathrm{~mm}$, compared with the corresponding "ideal repair."
\end{abstract}

Results: Despite the absence of residual regurgitation, alterations in chordal forces and leaflet stresses arose simulating suboptimal repairs; alterations were increasingly relevant as more complex prolapse anatomies were considered and were worst when simulating single neochorda implantation. Multiple chordae implantations were less sensitive to errors in neochordal length tuning, but associated postoperative biomechanics were hampered when asymmetric configurations were reproduced. Computational outcomes were consistent with the presence and entity of recurrent mitral regurgitation at midterm follow-up of simulated patients.

Conclusions: Suboptimal suture length tuning significantly alters chordal forces and leaflet stresses, which may be key parameters in determining the long-term outcome of the repair. The comparison of the different simulated techniques suggests possible criteria for the selection and implementation of neochordae implantation techniques. (J Thorac Cardiovasc Surg 2015;150:1303-12)

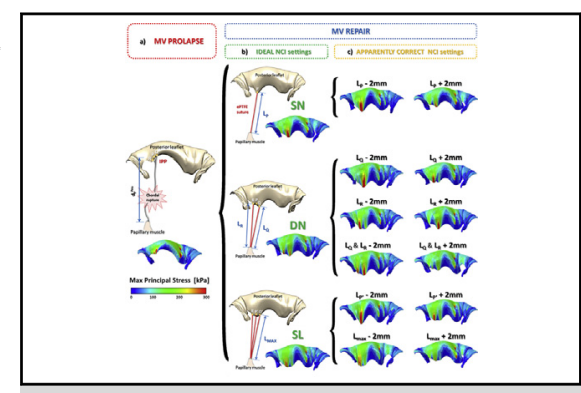

Study workflow: simulations of mitral prolapse and ideal and suboptimal mitral repairs.

Central Message

Millimetric suboptimal suture length during mitral plasty induces significant biomechanical consequences on the entire mitral apparatus.

Perspective

Mitral neochordoplasty largely depends on the intraoperative assessment of the appropriate length of artificial sutures. Patient-specific numeric models can explain the biomechanical drawbacks due to a suboptimal millimetric tuning of suture length, elucidate their relationship with patient-specific features and neochordal suture lengths, and lead the way to a more reproducible and effective surgery.

See Editorial Commentary page 1312.

\footnotetext{
From the ${ }^{\mathrm{a}}$ Division of Cardiovascular Surgery, Università degli Studi di Verona, Verona, Italy; ${ }^{b}$ Department of Electronics, Information, and Bioengineering, Politecnico di Milano, Milano, Italy; Departments of ${ }^{\mathrm{c}}$ Anesthesia and ${ }^{\mathrm{d}}$ Radiology, Università degli Studi di Verona, Verona, Italy.

Received for publication May 12, 2015; revisions received June 22, 2015; accepted for publication July 5, 2015; available ahead of print Aug 12, 2015.

Address for reprints: Francesco Sturla, PhD, Department of Electronics, Information, and Bioengineering, University of Verona Medical School, Politecnico di Milano, Via Golgi 39, 20133 Milano, Italy (E-mail: francesco.sturla@polimi.it or francesco.sturla@univr.it).

$0022-5223 / \$ 36.00$

Copyright (C) 2015 by The American Association for Thoracic Surgery

http://dx.doi.org/10.1016/j.jtcvs.2015.07.014
}

Supplemental material is available online.

Mitral valve (MV) plasty has successfully superseded valve replacement as the standard method for the treatment of degenerative MV prolapse. ${ }^{1,2}$ Several well-described approaches are currently available from leaflet resection to expanded polytetrafluoroethylene (ePTFE) neochordal implantation (NCI), with both surgical approaches associated 


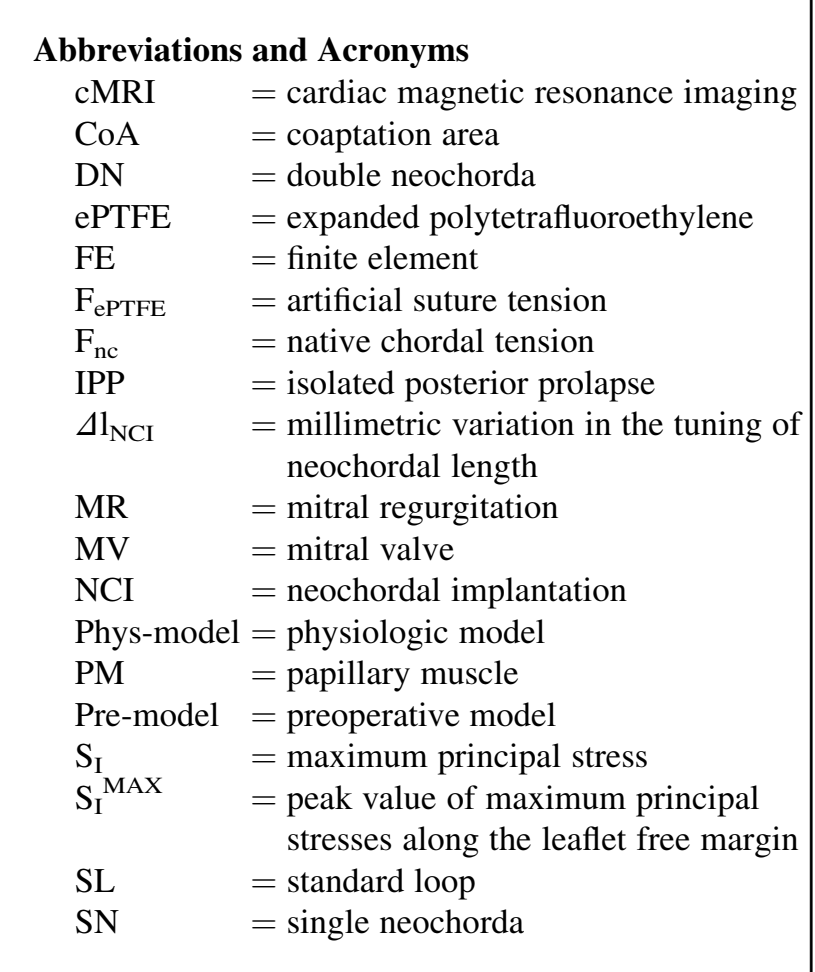

with excellent results in early and late outcomes. ${ }^{3-5}$ Since the clinical introduction of NCI in the late 1980s, the procedure has become an established technique ${ }^{6,7}$ proven to be safe and effective for both the anterior and posterior leaflets, ${ }^{8}$ allowing for a more physiologic repair with preserved leaflet mobility compared with resection techniques. However, the results of NCI largely depend on the appropriate number and length of the ePTFE sutures, ${ }^{9}$ which are still highly demanding issues, almost entirely based on the surgeon's expertise. ${ }^{10-13}$ Furthermore, when tuning the proper repair configuration with NCI, surgeons may have to progressively adjust the initially attempted repair to overcome residual mitral regurgitation (MR), although at the price of a longer and more difficult procedure. Therefore, a better understanding of the biomechanical effects of different NCI techniques on the MV apparatus and their relationship with patient-specific features and neochordal suture lengths may lead the way to a more reproducible and effective surgery, thus avoiding potential biomechanical drawbacks associated with a suboptimal repair. This aim can be pursued by means of finite element (FE) modeling, widely adopted today for the numeric analysis of the MV. ${ }^{14-16}$

\section{MATERIALS AND METHODS \\ Background of the Present Study}

In a recent study, ${ }^{17}$ we adopted patient-specific FE models to quantify the biomechanical effects of different ePTFE neochordal techniques in different morphologies of MV isolated posterior prolapse (IPP). Our results strongly suggested that different $\mathrm{NCI}$ techniques may equivalently recover MV coaptation while inducing notably different biomechanical consequences on the surrounding tissues, potentially affecting postoperative remodeling. These differences were dependent on both NCI techniques and patient-specific IPP. However, "ideal" NCI techniques may require millimetric adjustments, which are difficult to obtain in the "real daily surgical world" because of the subjective nature of manual surgical gestures.

In the present work, using different NCI techniques, we evaluated the biomechanical effects of apparently correct repairs (ie, without residual MR) due to a suboptimal millimetric ePTFE suture length.

\section{Patient-Specific Mitral Valve Finite Element Modeling}

The institutional review board approved the study, and informed consent was obtained from all patients. Four patients in stable sinus rhythm were selected from 20 contemporary cases affected by fibroelastic deficiency and scheduled for surgical repair of IPP due to chordal rupture. Selected patients fit the paradigm of a candidate for $\mathrm{NCI}$, in that they had $\mathrm{P} 2$ prolapse characterized by different IPP mechanisms: single primary chordal rupture anchoring on mid-P2 (patients 1 and 4); triple primary chordal rupture anchoring on mid-P2 (patient 2); and single paracommissural, between P2 and P3 scallops, primary chordal rupture (patient 3 ) ${ }^{17}$ Cardiac magnetic resonance imaging (cMRI) acquisitions were preoperatively performed on the selected patients through a 3.0T TX Achieva system (Philips Medical System, Irvine, Calif), with 1.25-mm in-plane resolution and 8-mm slice thickness, following a well-established protocol of acquisition. ${ }^{18}$ With the use of dedicated software (MATLAB, The MathWorks Inc, Natick, Mass), reference points were manually traced on all MV substructures in the end-diastolic frame (ie, the last frame preceding transient leaflets closure) and used to obtain the 3-dimensional model of the MV apparatus, which was assumed to be stress-free in this condition. ${ }^{14,18}$ The 3-dimensional model was refined on the basis of intraoperative measurements of the annulus to free edge extent of the MV leaflets at different reference points and on details of the IPP lesion (eg, number and type of the chordae involved, papillary muscle [PM], and posterior leaflet insertion). Models were completed by a realistic description of the stress-strain response of MV tissues and ePTFE neochordae. ${ }^{17,18}$

The mitral annulus and PMs were traced on cMRI frames from end diastole to peak systole (ie, the mid-systolic frame within the R-R interval) to derive the respective motion, which was imposed as a boundary condition together with a standard time-dependent transvalvular pressure load to simulate MV closure from end diastole to peak systole. The commercial solver ABAQUS Explicit 6.10 (SIMULIA, Dassault Systèmes, Vélizy-Villacoublay, France) was used.

With this simulation setup, the following 3 general conditions were analyzed for each MV (Figure 1):

- Physiologic model (Phys-model), characterized by an intact chordal apparatus and providing the physiologic level of MV coaptation and distance between the insertion of the ruptured chordae and the corresponding PM head.

- Preoperative model (Pre-model), reproducing the actual MV lesion and dysfunction (Figure 1, A).

- Postoperative models (NCI models), reproducing 3 different NCI techniques: single neochorda ( $\mathrm{SN}$ ), double neochorda (DN), and a standard loop (SL) consisting of 3 premeasured neochordae of the same length anchored to the PM tip (Figure $1, B$ and $C$ ). ${ }^{17}$ For each technique, an "ideal" setting and several suboptimal although realistic settings (named "apparently correct") were simulated. In the "ideal" SN and DN, neochordal length was tuned to reproduce the distance between the PM tip and the "leaflet" sites of NCI, as computed in the Phys-model. In the ideal SL, the length of each loop was equal to the maximal distance $\left(\mathrm{L}_{\max }\right)$ of the 3 insertion points from the PM tip, as computed in the Phys-model (Figure 1, B). Conversely, "apparently correct" settings of NCI techniques were simulated as follows: $\mathrm{SN}$ with ideal suture length altered by $\pm 2 \mathrm{~mm}\left(\mathrm{~L}_{\mathrm{P}} \pm 2 \mathrm{~mm}\right)$; DN with separate alteration by $\pm 2 \mathrm{~mm}$ of each single ideal neochorda $\left(\mathrm{L}_{\mathrm{Q}} \pm 2 \mathrm{~mm}, \mathrm{~L}_{\mathrm{R}} \pm 2 \mathrm{~mm}\right)$ or alteration of both ideal sutures $\left(\mathrm{L}_{\mathrm{Q}}\right.$ and $\left.\mathrm{L}_{\mathrm{R}} \pm 2 \mathrm{~mm}\right)$; $\mathrm{SL}$ with the length of the 3 loops 


\section{A MV PROLAPSE}

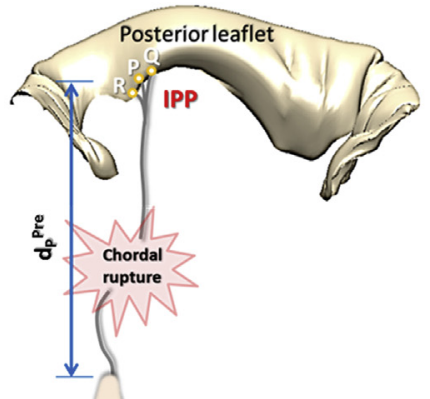

Papillary muscle

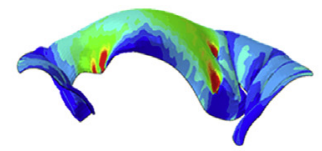

Max Principal Stress [kPa]

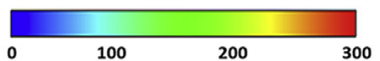

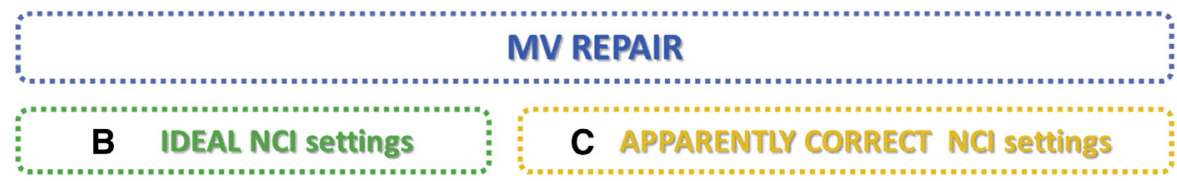
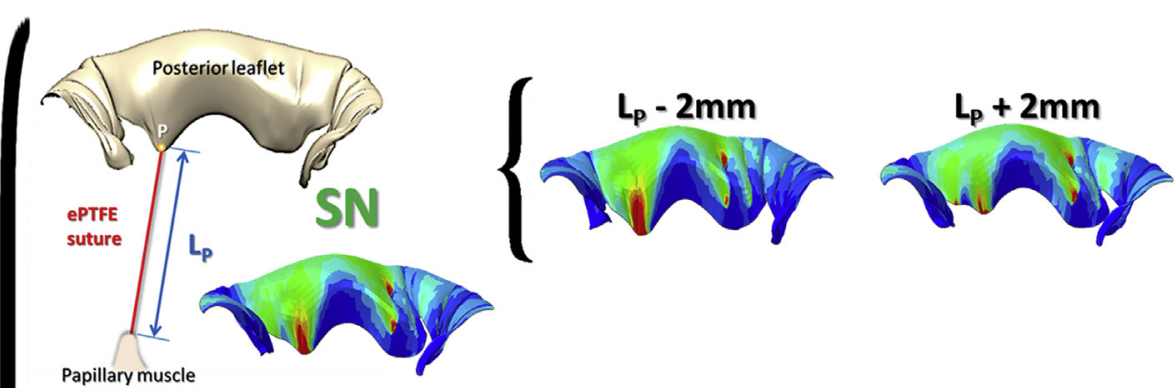

Papillary muscle
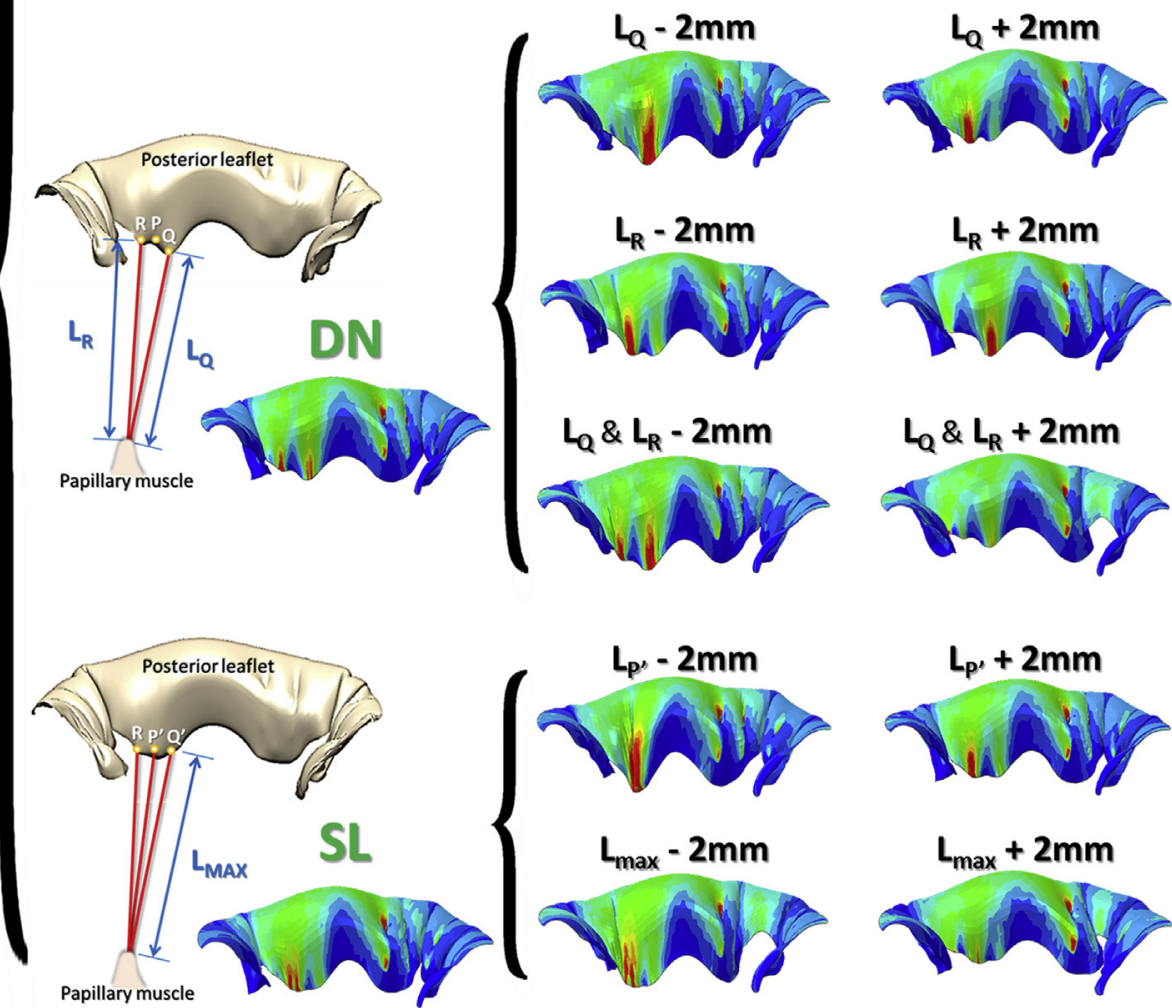

FIGURE 1. Study workflow: MV numeric simulation of patient-specific IPP geometry in patient 2 (A) and mechanical stress redistribution on the prolapsing MV posterior leaflet. B, Simulated standard NCI techniques adopting an ideal setting of NCI tuning (SN, DN, and SL) and systolic mechanical stress in postoperative conditions on the posterior MV leaflet. C, Simulation of postoperative MV systolic function after MV repair using the same NCI techniques and taking a realistic tuning of neochordal length into account. $M V$, Mitral valve; $N C I$, neochordal implantation; $e P T F E$, expanded polytetrafluoroethylene; $S N$, single neochorda; $I P P$, isolated posterior prolapse; $D N$, double neochorda; $S L$, standard loop.

concomitantly altered by $\pm 2 \mathrm{~mm}\left(\mathrm{~L}_{\max } \pm 2 \mathrm{~mm}\right)$ or with a $\pm 2 \mathrm{~mm}$ error in the tuning of the central loop only $\mathrm{L}_{\mathrm{P}^{\prime}} \pm 2 \mathrm{~mm}$ (Figure 1,C).

As a result, 17 simulations were run for each patient, 12 of which reproduced the 3 different simulated NCI techniques with an "apparently correct" (ie, suboptimal) level of precision in tuning neochordal length. For each simulated condition, the following biomechanical parameters were calculated at peak systole (Figure 2).

- Coaptation area (CoA), measured as the total extent of the elements in the posterior leaflet characterized by positive contact pressure.
- Peak value $\left(\mathrm{S}_{\mathrm{I}}^{\mathrm{MAX}}\right)$ of leaflet maximum principal stress $\left(\mathrm{S}_{\mathrm{I}}\right)$, that is, the maximum tensile stress at each point, next to the site of NCI.

- Artificial suture tension $\left(\mathrm{F}_{\mathrm{ePTFE}}\right)$ and sum of forces exerted by the native chordae tendineae adjacent to the site of $\mathrm{NCI}\left(\mathrm{F}_{\mathrm{nc}}\right)$.

\section{RESULTS}

\section{Mitral Valve Prolapse}

A similar pattern of detrimental effects was reported in MV biomechanics for all Pre-models (Tables E1 and E2). 
A

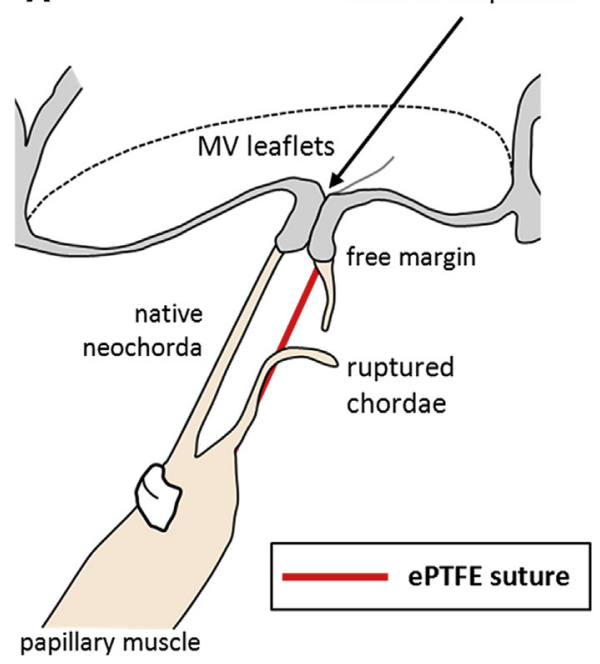

B

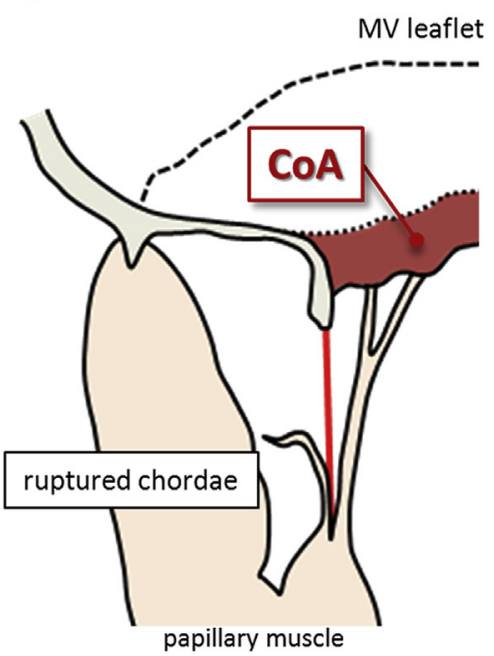

C

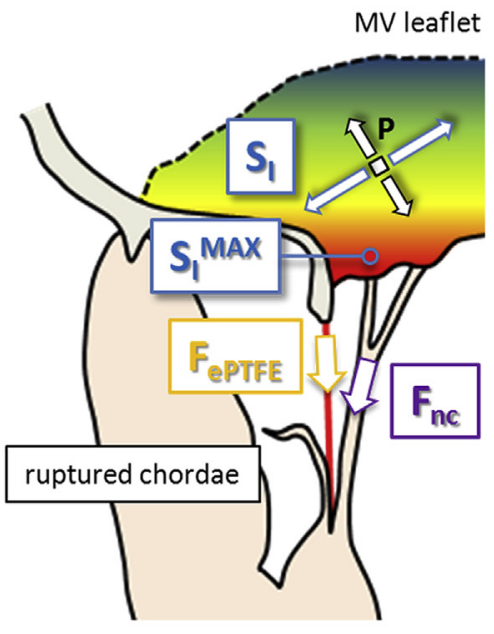

FIGURE 2. A, Sketch of the MV in its closed configuration depicting the region of coaptation (black arrow), the ruptured native chordae, and the ePTFE suture (red line). B, Representation of the CoA, identified by the region where mechanical interaction between the mitral leaflets (ie, contact pressure) was computed at peak systole. CoA was quantified as the sum of the areas of the triangular elements where positive contact pressure was obtained. C, Representation of the computed biomechanical variables. $F_{\text {ePTFE }}$ and $F_{n c}$ represent the tension (ie, the axial force) acting on the ePTFE suture and the adjacent native chordae, respectively. $\mathrm{S}_{\mathrm{I}}$ is the maximum principal stress over the mitral leaflets: At every point, an infinitesimal portion of tissue is considered, and the stresses acting on it are analyzed in a local reference frame where no shear stresses are present, and the maximum possible tension at that point $(\mathrm{P})$ is $\mathrm{S}_{\mathrm{I}}$. The peak value of $\mathrm{S}_{\mathrm{I}}$ over the leaflets (located in the red region) is $\mathrm{S}_{\mathrm{I}}^{\mathrm{MAX}}$. $M V$, Mitral valve; $C o A$, coaptation area; $S_{I}$, maximum principal stress; $S_{I}^{M A X}$, peak value of maximum principal stresses along the leaflet free margin; $F_{e P T F E}$, artificial suture tension; $F_{n c}$, native chordal tension; $e P T F E$, expanded polytetrafluoroethylene.

As a result of IPP, coaptation was absent in the prolapsing region, low $S_{I}$ values were identified in the prolapsing region, and stress concentrations were computed at the insertions of the adjacent residual native chordae.

\section{Effects of Simulated Mitral Valve Repair}

The CoA values are reported in Table E1 and Figure 3 (red histograms). When the "ideal" settings of SN, DN, and SL were considered, different results were obtained for the 4 patients (Figure 3, red lines and vertical dotted lines). In patients 1 to 3 , for every considered "ideal" NCI technique, the postoperative CoA was smaller than the one obtained in the corresponding Phys-model. Differences with respect to Phys-model were inferior to $3 \%$ for at least 1 technique with multiple neochordae (eg, SL for patient 1, DN for patients 2 and 3), with $\mathrm{SN}$ always being the least effective technique. On the contrary, in patient 4 , the postoperative "ideal" CoA was always higher (by $8 \%$ to $9 \%$ ) compared with the Phys-model, regardless of the simulated NCI technique.

When the "apparently correct" setting of NCI techniques was considered, competence was restored in any case (Figure E1) with a CoA value in each patient, always higher than the corresponding Pre-model. However, millimetric variation in the tuning of neochordal length $\left(\Delta \mathrm{l}_{\mathrm{NCI}}\right)$ had different impacts on the 4 simulated MVs: In patient 4 , postoperative CoA values changed with respect to the corresponding "ideal" setting of NCI, with changes ranging from $-7.6 \%$ and $+4.2 \%$ based on the specific simulated technique, although CoA always resulted in significantly higher values than the Pre-model and Phys-model. In patients 1 and 2, CoAs were greater than the Pre-model with all simulated NCI techniques, although some of these had such a critical response to $\Delta \mathrm{l}_{\mathrm{NCI}}$ to result in CoA values far from the "ideal" and approximating Pre-model values, although they still allowed for MV competence (eg, SL with $\mathrm{L}_{\mathrm{MAX}}+2 \mathrm{~mm}$ simulated on patient 1 and DN with $\mathrm{L}_{\mathrm{Q}}+2 \mathrm{~mm}$ simulated on patient 2 yielded a minimal recovery of CoA of only $4.2 \%$ and $1.1 \%$ compared with the Premodel, respectively). In patient $3, \mathrm{CoA}$ response to $\Delta \mathrm{l}_{\mathrm{NCI}}$ was even more evident than in patients 1 and 2. In most simulated NCI scenarios, physiologic-like values of CoA were computed, but in some cases "apparently correct" NCI led to wider CoA compared with the "ideal" model (eg, $+32.0 \%$ in $\mathrm{SN}$ with $\mathrm{L}_{\mathrm{P}}-2 \mathrm{~mm}$ vs "ideal" $\mathrm{SN}$, and $+9.7 \%$ in SL with $\mathrm{L}_{\mathrm{P}^{\prime}}-2 \mathrm{~mm}$ vs "ideal" $\mathrm{SL}$ ) (Figure 3) and in others to nearly pathologic CoA values (eg, DN with $\mathrm{L}_{\mathrm{R}}+2 \mathrm{~mm}-15.8 \%$ vs "ideal" $\mathrm{DN}$ and $+5.5 \%$ vs Pre-model; SL with $\mathrm{L}_{\mathrm{Lmax}}+2 \mathrm{~mm}-17.3 \%$ vs "ideal" SL and $+1.7 \%$ vs Pre-model).

Stress analysis. $\mathrm{S}_{\mathrm{I}}{ }^{\mathrm{MAX}}$ values are shown in Table E1 and Figure 3 (blue histograms). In patients 1, 2, and 4, the simulated "ideal" settings of SN, DN, and SL (Figure 3, blue lines and vertical dotted lines) led to a decrease of $\mathrm{S}_{\mathrm{I}}$ MAX 
Patient 1

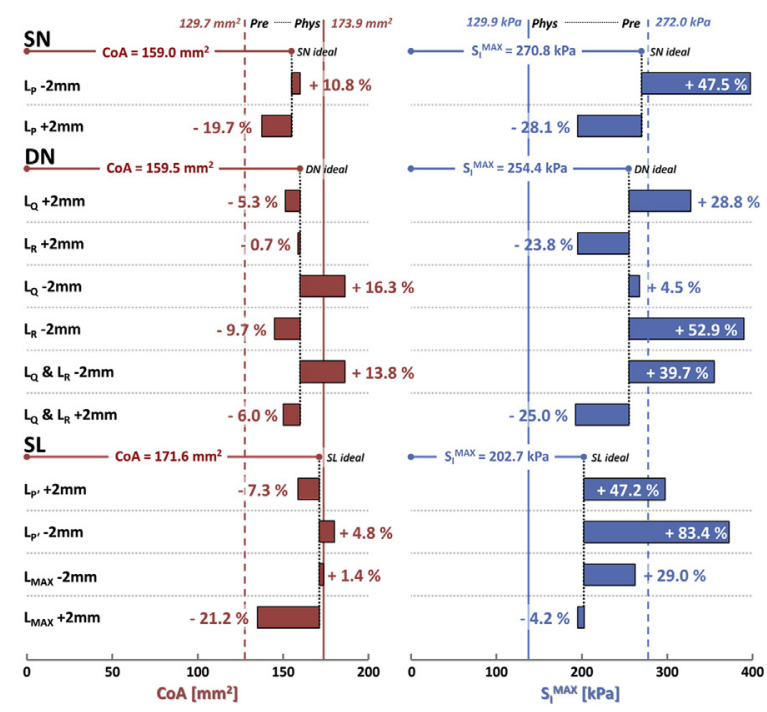

Patient 3

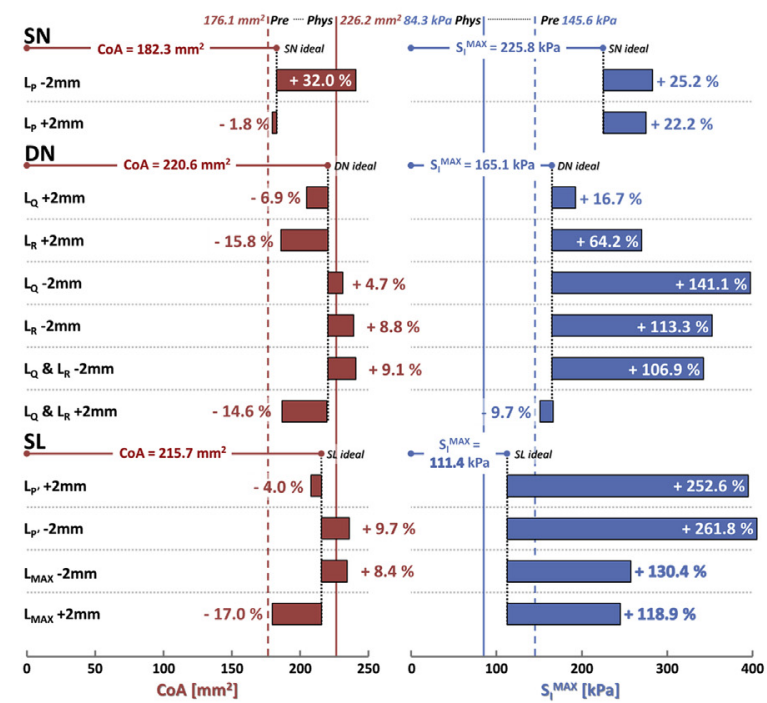

Patient 2

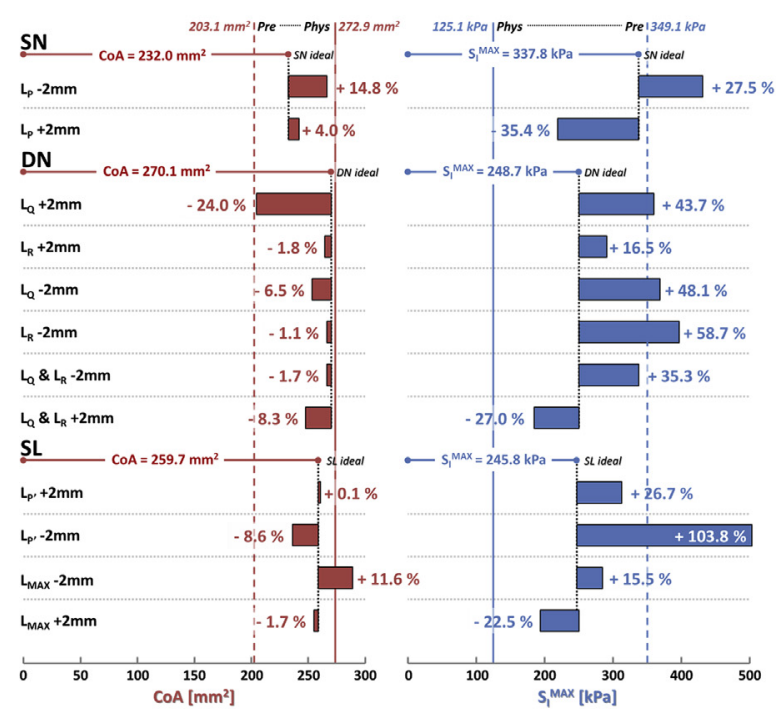

Patient 4

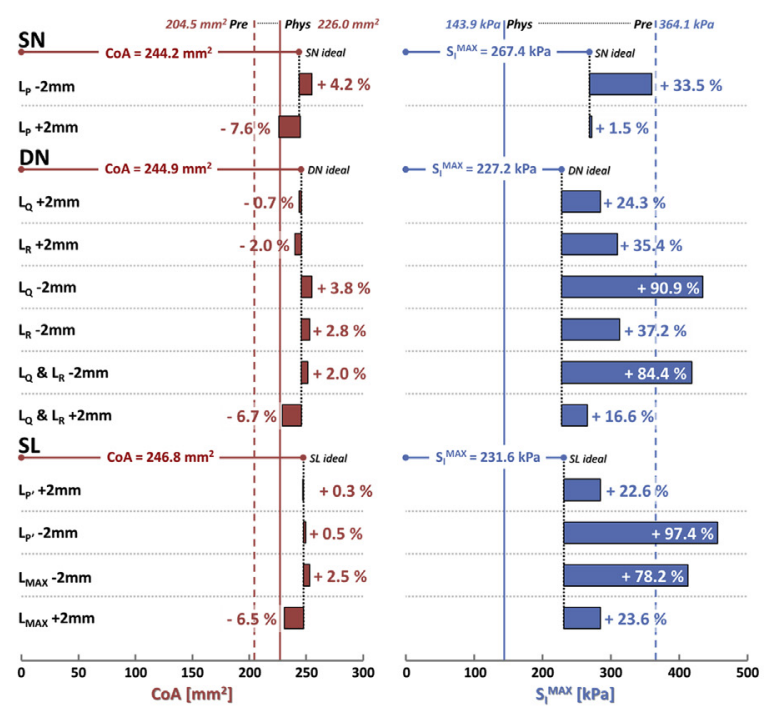

FIGURE 3. Percentage variation, with respect to the corresponding "ideal" SN, DN, and SL repair, of the computed CoA (red bars) and peak of mechanical principal stress $\left(\mathrm{S}_{\mathrm{I}}^{\mathrm{MAX}}\right.$, blue bars) for each tested "apparently correct" configuration. Absolute values of CoA and $\mathrm{S}_{\mathrm{I}}^{\mathrm{MAX}}$ are provided for each "ideal" $\mathrm{SN}, \mathrm{DN}$, and SL configuration (using a horizontal colored line); the percentage variation for each "apparently correct" configuration is reported with respect to the corresponding "ideal" MV repair. The range of variability between the preoperative condition (Pre-model, dotted vertical line) and the physiologic state (Phys-model, continuous vertical line) for each reported variable. All the reported "apparently correct" configurations are detailed in the section "Patient-Specific Mitral Valve Finite Element Modeling." $S N$, Single neochorda; $D N$, double neochorda; $S L$, standard loop; $C o A$, coaptation area; $S_{I}^{M A X}$, peak value of maximum principal stresses along the leaflet free margin.

in the region of the prolapsing scallop subtended by native chordae and to a technique-specific redistribution of mechanical stress close to neochordal insertions with respect to the Pre-model. In patient $3, \mathrm{~S}_{\mathrm{I}}^{\mathrm{MAX}}$ decreased with respect to the Pre-model only when the SL technique was simulated. In all patients, stress reduction was more marked in case of multiple neochordae insertion compared with $\mathrm{SN}$, for example, up to $29.6 \%$ with an SL ideal configuration in patient 2 and $37.6 \%$ with a DN ideal configuration in patient 4 .
When simulating "apparently correct" NCI settings, a systematic $\mathrm{S}_{1}{ }^{\mathrm{MAX}}$ increase was noticed with a $-2 \mathrm{~mm} \Delta \mathrm{l}_{\mathrm{NCI}}$, whereas in case of $+2 \mathrm{~mm} \Delta \mathrm{l}_{\mathrm{NCI}}$ the changes in $\mathrm{S}_{1}{ }^{\mathrm{MAX}}$ were IPP specific (Figure 3). For instance, in the SN, a 2-mm shortening increased $\mathrm{S}_{\mathrm{I}}{ }^{\mathrm{MAX}}$ in a range from $25.2 \%$ (patient 3) to $47.5 \%$ (patient 1 ) versus corresponding "ideal" settings, whereas the simulation of a 2-mm looser neochorda, depending on the patient-specific IPP morphology, led to different $\mathrm{S}_{\mathrm{I}} \mathrm{MAX}$ changes ranging from $-35.4 \%$ in patient 
2 to $+22.2 \%$ in patient 3 versus a corresponding "ideal" $\mathrm{SN}$. In the DN, a 2-mm shortening of 1 or both neochordae always led to a $S_{I}$ increase. On the one hand, the highest stresses were computed in each patient when only 1 neochorda was shortened $\left(\mathrm{S}_{\mathrm{I}}^{\mathrm{MAX}}\right.$ increased from $52.9 \%$ in patient 1 to $141.1 \%$ in patient 3 vs corresponding "ideal" $\mathrm{DN})$. On the other hand, when both neochordae were $2 \mathrm{~mm}$ looser, $\mathrm{S}_{\mathrm{I}}{ }^{\mathrm{MAX}}$ was least affected with variations from $-27 \%$ in patient 2 to $+16.6 \%$ in patient 4 versus the corresponding "ideal" DN. In the SL, the highest impact of $-2 \mathrm{~mm} \Delta \mathrm{l}_{\mathrm{NCI}}$ on $\mathrm{S}_{\mathrm{I}}{ }^{\mathrm{MAX}}$ was observed, with the most notable $\mathrm{S}_{\mathrm{I}}{ }^{\mathrm{MAX}}$ increase due to a 2-mm shortening of the central suture (SL with $\mathrm{L}_{\mathrm{P}^{\prime}}-2 \mathrm{~mm}$, from $+83.4 \%$ in patient 1 to $+261.8 \%$ in patient 3 vs corresponding "ideal" SL). The impact of $+2 \mathrm{~mm} \Delta \mathrm{l}_{\mathrm{NCI}}$ on $\mathrm{S}_{\mathrm{I}}^{\mathrm{MAX}}$ after SL was IPP dependent, and $\mathrm{S}_{\mathrm{I}}{ }^{\mathrm{MAX}}$ was augmented in almost all cases, from $+22.6 \%$ in patient 4 (SL with $\mathrm{L}_{\mathrm{P}^{\prime}}+2 \mathrm{~mm}$ ) to $+252.6 \%$ in patient 3 (SL with $\mathrm{L}_{\mathrm{P}^{\prime}}+2 \mathrm{~mm}$ ), with respect to corresponding "ideal" SL; $\mathrm{S}_{\mathrm{I}}{ }^{\mathrm{MAX}}$ was reduced only simulating SL with $\mathrm{L}_{\mathrm{MAX}}+2 \mathrm{~mm}$ in patient $1(-4.2 \%)$ and patient $2(-22.5 \%)$. Chordal and neochordal forces. Forces on ePTFE sutures $\left(\mathrm{F}_{\mathrm{ePTFE}}\right)$ and on the adjacent native chordae tendineae $\left(\mathrm{F}_{\mathrm{nc}}\right)$ are reported in Table E2 and Figure 4. When "ideal" NCI settings were considered, $F_{n c}$ was always markedly lowered with respect to the Pre-model. In patients 1, 2, and 4, multiple chordae techniques (DN or $\mathrm{SL}$ ) resulted in physiologic-like $\mathrm{F}_{\mathrm{nc}}$ values (differences from $-1.7 \%$ with $\mathrm{DN}$ in patient 2 to $+15.2 \%$ with $\mathrm{DN}$ in patient 1 vs corresponding Phys-model), and a smaller $\mathrm{F}_{\mathrm{nc}}$ reduction was obtained when simulating $\mathrm{SN}$. This trend was not confirmed in patient 3 , in whom the maximum relief was obtained with the "ideal" DN technique and the worst relief with the "ideal" SL. Changes in $F_{n c}$ were consistent with those in $F_{e P T F E} ; F_{e P T F E}$ increased as $F_{n c}$ decreased and vice versa. Of course, in the $\mathrm{SN}$ ideal configuration, $\mathrm{F}_{\mathrm{ePTFE}}$ was borne by the only implanted neochorda (orange box in Figure 4), whereas a less obvious outcome was obtained with the "ideal" DN and SL, which did not evenly distribute loads among the neochordae (ie, 50\%/neochorda in DN and $\sim 33 \%$ /neochorda in SL) (Figure 4).

When "apparently correct" NCI settings were considered, a $+2 \mathrm{~mm} \Delta \mathrm{l}_{\mathrm{NCI}}$ almost always resulted in lower $\mathrm{F}_{\mathrm{ePTFE}}$ values and higher $F_{n c}$ values compared with the corresponding "ideal" configuration, with opposite results (ie, $\mathrm{F}_{\mathrm{ePTFE}}$ augmentation and $\mathrm{F}_{\mathrm{nc}}$ reduction) with $-2 \mathrm{~mm} \Delta \mathrm{l}_{\mathrm{NCI}}$. However, in the DN and SL configurations of patient $3, \pm 2 \mathrm{~mm}$ $\Delta \mathrm{l}_{\mathrm{NCI}}$ changes, in 1 or all neochordal lengths, did not necessarily result in opposite changes between $\mathrm{F}_{\mathrm{ePTFE}}$ and $\mathrm{F}_{\mathrm{nc}}$ (Figure 4). Moreover, changes in $\mathrm{F}_{\mathrm{ePTFE}}$ in "apparently correct" repairs reported a wider range of variations (from $-59.8 \%$ in patient 4 with SL $\mathrm{L}_{\mathrm{MAX}}+2 \mathrm{~mm}$ to $73.8 \%$ in patient 3 with $\mathrm{DN} \mathrm{L}_{\mathrm{Q}}$ and $\mathrm{L}_{\mathrm{R}}+2 \mathrm{~mm}$ ) than in $\mathrm{F}_{\mathrm{nc}}$ (from $-26.7 \%$ in patient 2 with $\mathrm{SL} \mathrm{L}_{\mathrm{MAX}}-2 \mathrm{~mm}$ to $+39.8 \%$ in patient 3 with $\mathrm{DN} \mathrm{L}_{\mathrm{Q}}$ and $\mathrm{L}_{\mathrm{R}}+2 \mathrm{~mm}$ ). Of note, the most evident consequence of $2 \mathrm{~mm}$ longer or shorter neochordae was the unbalance in $\mathrm{F}_{\mathrm{ePTFE}}$ repartition when multiple suture techniques were simulated. For instance, a 2-mm shortening of 1 suture in the SL technique resulted in only the shorter 1 (of 3) bearing the entire (patients 1,2, and 4) or almost the entire load (patient 3 ).

Biomechanical "Holistic" interpretation of data. MV biomechanics-in terms of CoA, $\mathrm{S}_{\mathrm{I}}^{\mathrm{MAX}}, \mathrm{F}_{\mathrm{nc}}$, and $\mathrm{F}_{\mathrm{ePTFE}}$ - is comprehensively summarized for each patientspecific scenario through radar charts (Figure E2), pointing out the variation of each computed variable for all the simulated "ideal" and "apparently correct" NCI techniques.

\section{Surgery and Echocardiographic Follow-up}

Patient 1 underwent SN implantation on the central P2 scallop, and echocardiographic assessment reported excellent results up to postoperative month 9, when trivial residual MR was noticed. The last echocardiographic assessment at postoperative month 31 confirmed mild MR with a vena contracta of $0.4 \mathrm{~cm}$ and a regurgitant volume of $30 \mathrm{~mL}$.

Patient 2 underwent DN implantation with 1 ePTFE neochorda from the anterior PM to the lateral portion of P2 scallop and the other one from the posterior PM to the medial portion of the $\mathrm{P} 2$ scallop. Excellent acute procedural success was reported; no residual MR has been detected up to the last echocardiographic assessment at postoperative month 21.

Patient 3 underwent SN implantation on the P2-P3 region. Despite intraoperative transesophageal echocardiography and predischarge transthoracic echocardiography showing excellent surgical results with no residual MR, trivial MR recurrence was observed at postoperative month 2 , which further evolved to mild MR at postoperative month 22 and finally evolved into mild-moderate MR with a regurgitant volume of $44 \mathrm{~mL}$ and an effective regurgitant orifice area of $0.3 \mathrm{~cm}^{2}$ at the last assessment (postoperative month 27).

Patient 4 underwent localized P2 quadrangular resection complemented by sliding plasty. Predischarge transthoracic echocardiography reported trivial MR that remained stable at the last echocardiographic assessment at postoperative month 18. All of the MV repairs were complemented by an exactly sized annuloplasty with an autologous pericardial band.

\section{DISCUSSION}

In our previous study, ${ }^{17}$ we used patient-specific cMRIderived FE models to pinpoint the biomechanical determinants underlying different NCI techniques, simulated assuming perfectly tuning of neochordal length. In that study, we showed that postoperative MV biomechanics associated with a specific NCI configuration strongly depends on the patient-specific IPP mechanism and suggested that NCI 
Patient 1
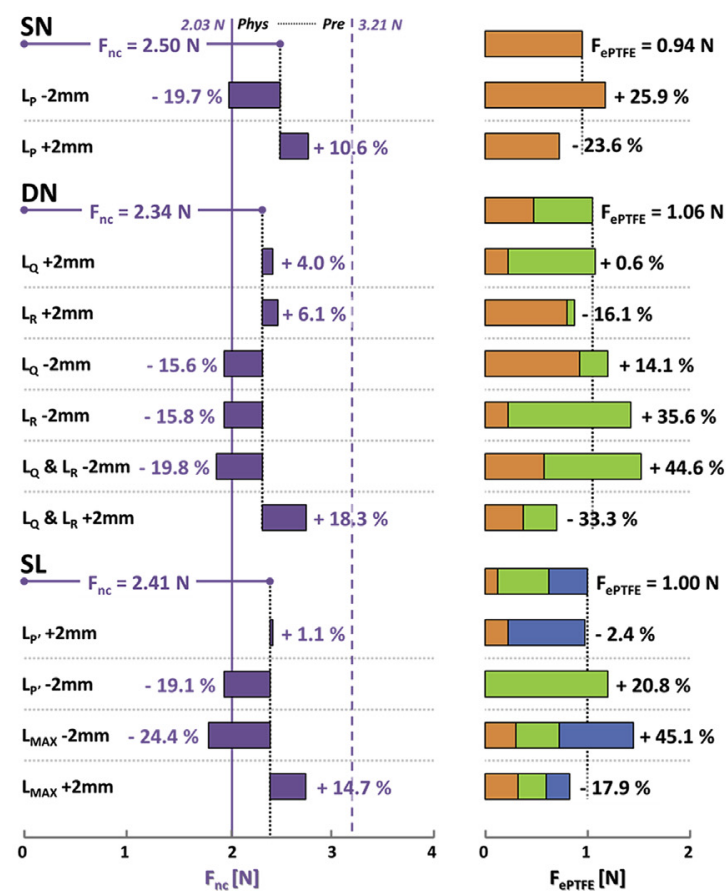

Patient 3

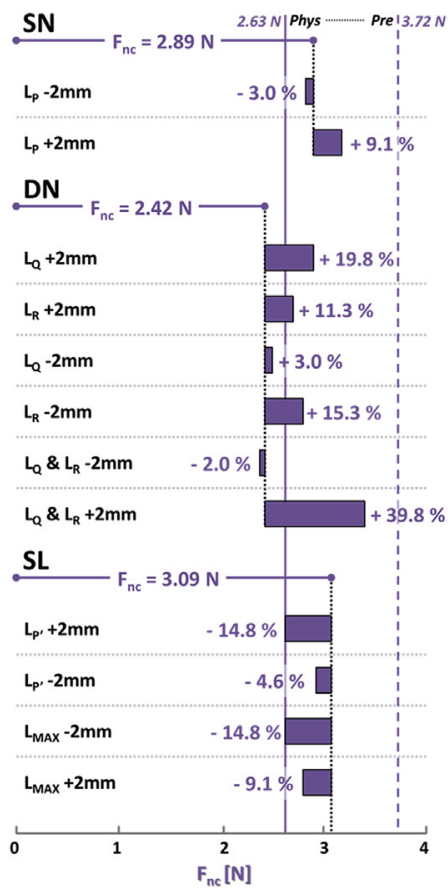

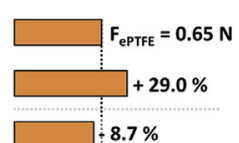
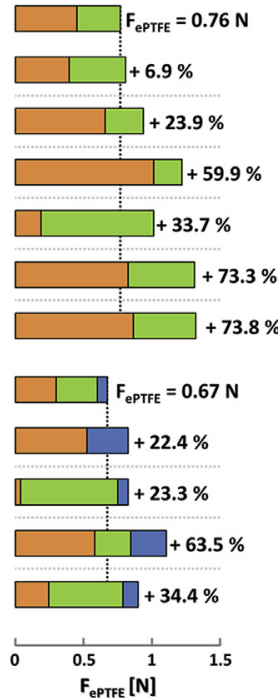

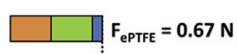

Patient 2

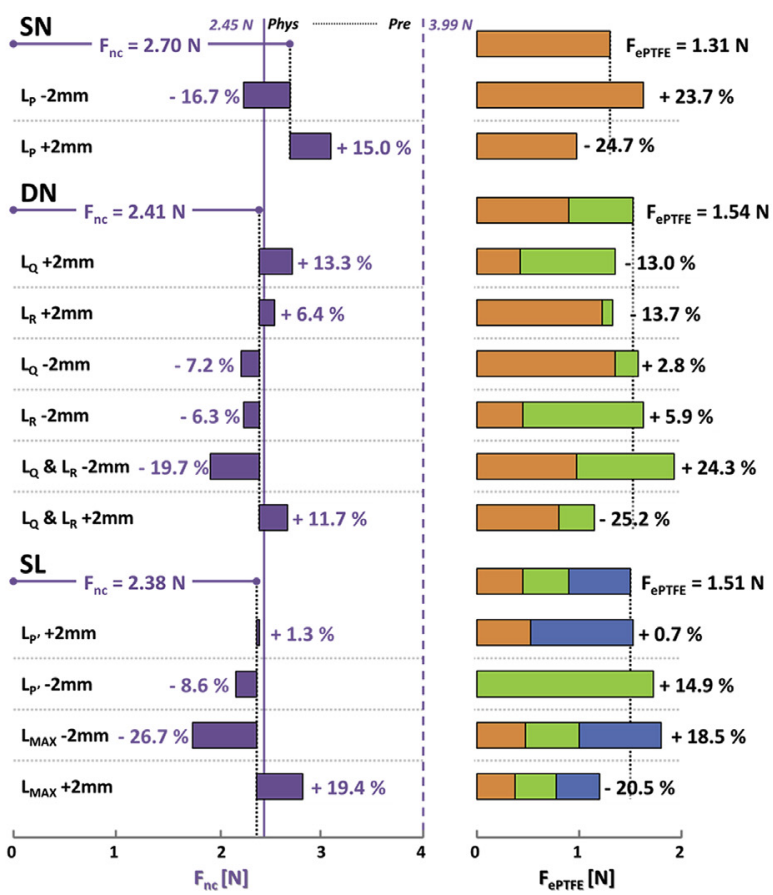

Patient 4

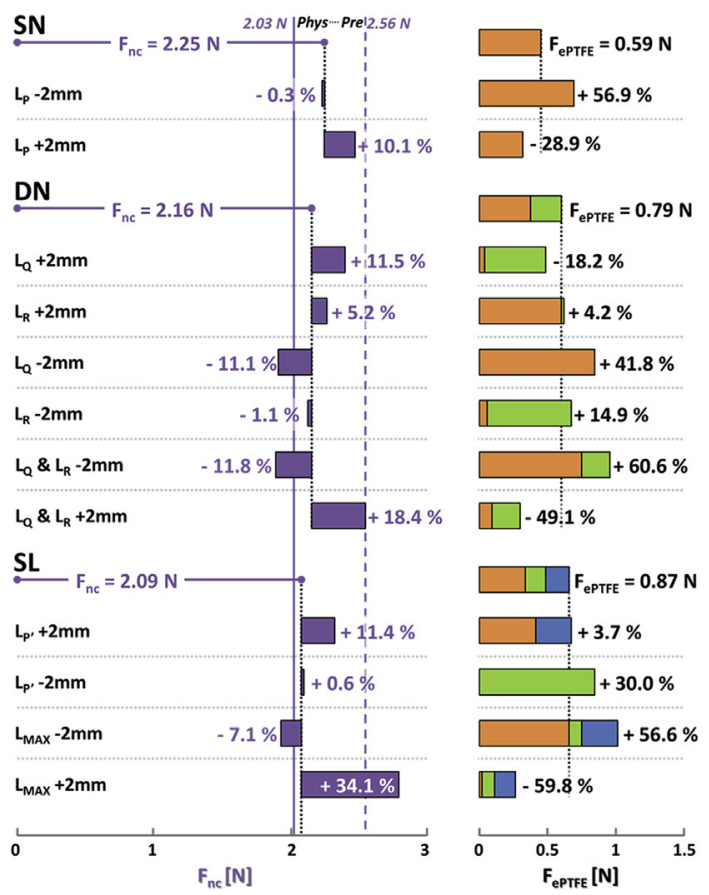

FIGURE 4. Percentage of variation, with respect to the corresponding "ideal" MV repair (ie, SN, DN, and SL, respectively), of the resultant force of native chordae $\left(\mathrm{F}_{\mathrm{nc}}\right.$, violet bars on the left of each panel) and the computed neochordal force ( $\mathrm{F}_{\mathrm{ePTFE}}$, on the right of each panel) for each tested "apparently correct" configuration. The range of variability is reported, for $\mathrm{F}_{\mathrm{nc}}$ resultant force, between the preoperative condition (Pre-model, dotted vertical line) and the physiologic state (Phys-model, continued vertical line). For each tested NCI multiple configuration, the percentage of redistribution of $\mathrm{F}_{\mathrm{ePTFE}}$ between implanted artificial sutures is reported with different colors on the bar (ie, orange, green, and light-blue colors are used when necessary). All the reported "apparently correct" configurations are detailed in the section "Patient-Specific Mitral Valve Finite Element Modeling." $S N$, Single neochorda; $F_{n c}$, native chordal tension; $F_{\text {ePTFE }}$, artificial suture tension. 
outcomes do not result from CoA restoration alone, but also from restoring physiologic-like tissue tensions.

In the present study, we extended our FE analysis to assess the impact of realistic millimetric errors $( \pm 2 \mathrm{~mm})$ in neochordal length tuning with 3 different NCI techniques. We assumed that such errors are a potential "surgical trap," that is, they may not cause residual regurgitation at the saline injection, and thus may not be detected intraoperatively but may cause the persistence of undesired tissue tensions, resulting, as reported by previous clinical studies, ${ }^{19,20}$ at follow-up in the recurrence of MV regurgitation due to valve-related (eg, progressive disease, endocarditis) and procedure-related (eg, suture dehiscence, incomplete initial correction) mechanisms of failure. ${ }^{21}$ Indeed, 3 of 4 patients enrolled in this series progressively developed some sort of residual although limited MR at follow-up. Although intraoperative transesophageal echocardiography confirmed excellent repairs, these follow-up echocardiographic findings might be explained by the reported biomechanical unbalances, possibly related to "suboptimal" repairs.

Our computational simulations confirmed our initial assumption. In all of the simulated post-NCI conditions, the MV was fully continent (Figure E1), but the leaflet stresses and forces in native and implanted chordae varied notably. The variations from technique to technique were subject-specific, but some common trends were evident. These data open the way to several clinical inferences reported next, which may play a role not only in open surgery but also in the emerging transapical approach to NCI. ${ }^{22-25}$

\section{Clinical Perspectives from Biomechanical Analyses} Dependence on isolated posterior leaflet prolapse mechanisms. Single chordal rupture (patients 1 and 4) can be considered a simpler IPP mechanism to repair compared with multiple chordal rupture (patient 2) or a para-medial prolapse ( $\mathrm{P} 2-\mathrm{P} 3$ prolapse in patient 3 ). In our simulations, variations in chordal forces and leaflet peak stresses associated with $\pm 2 \mathrm{~mm} \Delta \mathrm{l}_{\mathrm{NCI}}$ increased as progressively more complex IPP mechanisms were considered. Such variations were particularly severe in the most complex case, that is, patient 3 , who was the only case with moderate MR at follow-up, possibly related not only to the complex IPP anatomy but also to the "too elementary" repair accomplished through an SN.

Multiple neochordae are more effective than single neochorda. When simulating NCI techniques with "ideal" neochordal length tuning, multiple neochordae provided lower stresses compared with single chorda implantation. This difference increased as the complexity of the IPP increased (ie, progressing from patient 4 to patients 1,2, and 3). Also, when simulating "suboptimal repairs," we computed better biomechanical responses with multiple neochordal stitching, with loop techniques reporting the lowest sensibility to $\Delta \mathrm{l}_{\mathrm{NCI}}$, with the only exception of profoundly asymmetric repairs (Table E1). This result is particularly evident when comparing patient 2 (chordal rupture involving only mid-P2 treated with DN) with patient 3 (P2-P3 prolapse treated with $\mathrm{SN}$ ). When compared with the simulated pathologic condition (Pre-model), computed SN data for patient 3 showed an unloading of native chordae $\left(\mathrm{F}_{\mathrm{NC}}\right.$ reduced by $\left.15 \%-24 \%\right)$ but a very high increase of $\mathrm{S}_{\mathrm{I}}^{\mathrm{MAX}}(\sim+90 \%)$. Computed DN data of patient 2 showed a greater unloading of native chordae $\left(\mathrm{F}_{\mathrm{NC}}\right.$ reduced by $31 \%-51 \%$ ) because of the higher stiffness of the DN compared with the SN, with only a limited increase of $S_{I}{ }^{\mathrm{MAX}}(\leq 13 \%)$, because of the load transfer distributed over 2 points of neochordae insertion. These data seem to substantiate follow-up echocardiographic findings. At midterm follow-up, patient 3 presented recurrent moderate MR, whereas patient 2 was the only patient of this series with no recurrent MR, possibly because of not only the favorable anatomy of IPP but also the use of a DN.

Our computational and clinical results are also consistent with data from the first multicentric trial of the Neochord DS1000 System (NeoChord, Inc, Eden Prairie, Minn) for transapical NCI. ${ }^{23}$ Early neochordae dehiscence was reported for patients treated with an $\mathrm{SN}$, and a progressive increase in the 30-day success rate was observed when increasing the number of implanted neochordae. The hypothesized reasons for these results include the equal distribution of mechanical stress on MV leaflet tissue and polytetrafluoroethylene sutures when using multiple neochordae. ${ }^{23}$

Asymmetries in multiple chordae should be avoided. Both excessive shortening and excessive lengthening of neochordae led to an increase in leaflet stresses; peak stresses were detected next to the implanted sutures in the former case and at the insertions of the adjacent native chordae tendineae in the latter case. These results suggest that the key factor to avoid undesired leaflet peak stresses is obtaining a balance between the relieved systolic load of native chordae, to limit their possible postoperative remodeling and elongation, ${ }^{26}$ and the local load transfer from neochordae to leaflets. This concept becomes particularly evident when multiple neochordae implants are considered. The most notable increases in leaflet stresses were obtained when only the length of 1 neochorda was altered, thus obtaining an undesired asymmetry and an uneven distribution of load between neochordae and between those and the adjacent native chordae tendineae. For instance, in SL with $\mathrm{L}_{\mathrm{p}^{\prime}}-2 \mathrm{~mm}$, the $\mathrm{F}_{\mathrm{ePTFE}}$ load was entirely (patients 1 , 2 , and 4 ) or almost completely ( $87 \%$ of the load in patient 3 ) settled on a single suture; likewise, in patients 2 and 4 , DN with $\mathrm{L}_{\mathrm{Q}}-2 \mathrm{~mm}$ showed that only 1 suture, of the $2 \mathrm{im}$ planted neochordae, was loaded (Figure 4). Of note, in a recent study, transapical implantation of multiple neochordae was performed in 13 patients. Only 1 patient, initially treated by implanting 2 neochordae, had recurrent MR at 1 month due to dehiscence of 1 of the 2 implanted 
neochordae. ${ }^{25}$ It could be speculated that such "asymmetric" failure was associated with an asymmetric load transfer from neochordae to the leaflet.

\section{Study Limitations}

Four main limitations of the present study should be highlighted. First, our analysis required 17 different FE simulations for each selected patient with IPP, and each simulation required approximately 10 hours. Consequently, the present FE modeling cannot be used in the daily clinical routine as a surgical planning tool. However, it is intended as a speculative approach that aims at quantifying the effects on MV biomechanics of a realistic level of neochordal length tuning, thus further elucidating the determinants of a proper MV repair and the biomechanical drawbacks potentially leading to relapses at follow-up.

Second, for each NCI technique, variations in neochordal length different from $\Delta \mathrm{l}_{\mathrm{NCI}}= \pm 2 \mathrm{~mm}$ were not simulated. However, different values of $\Delta \mathrm{l}_{\mathrm{NCI}}$ will probably result in a "macroscopic" inadequate MV plasty, with persistent P2 prolapse $\left(\Delta \mathrm{l}_{\mathrm{NCI}}>>+2 \mathrm{~mm}\right)$ or excessive leaflet tethering $\left(\Delta \mathrm{l}_{\mathrm{NCI}}<<-2 \mathrm{~mm}\right)$, respectively. Conversely, smaller variations of neochordal length $\left(-1 \mathrm{~mm}<\Delta \mathrm{l}_{\mathrm{NCI}}<+1 \mathrm{~mm}\right)$, although possible while performing MV repair through artificial neochordae, were not considered beyond the intraoperative surgical perception.

Third, our comparison between computational results and follow-up evidences is speculative; we cannot confirm that "suboptimal" rather than "ideal" repairs were accomplished during surgery, because surgeons were not aware of the "ideal" technique at the time of intervention. To allow for a quantitative comparison of computational versus clinical data, a prospective study would be needed, and intraoperative and follow-up measurements should be planned ad hoc to be paired with computational data.

Fourth, our model is unable to predict clinical MR relapses, because it does not consider potential tissue remodeling associated with disease progression or induced by surgical repair. To be accounted for, these aspects should be modeled through a deterministic law, and a large amount of experimental data would be required to tune the parameters of the associated equations. For this reason, the precise prediction of MR recurrence is beyond the current capabilities of FE models.

\section{CONCLUSIONS}

Patient-specific FE simulations proved able to quantitatively assess the biomechanical effects of a millimetric suboptimal tuning of neochordal length during mitral neochordoplasty. Despite avoiding residual mitral regurgitation, a suboptimal suture length significantly alter chordal forces and leaflet stresses, which may be key parameters in determining the long-term outcome of the repair. The FE comparison of the different simulated techniques suggests possible criteria for the selection and implementation of neochordae implantation, potentially promoting a more reproducible and effective MV surgery.

\section{Conflict of Interest Statement}

Authors have nothing to disclose with regard to commercial support.

\section{References}

1. Sawazaki M, Tomari S, Zaikokuji K, Imaeda Y. Controversy in mitral valve repair, resection or chordal replacement? Gen Thorac Cardiovasc Surg. 2014; 62:581-5.

2. Enriquez-Sarano M, Schaff HV, Orszulak TA, Tajik AJ, Bailey KR, Frye RL. Valve repair improves the outcome of surgery for mitral regurgitation. A multivariate analysis. Circulation. 1995;91:1022-8.

3. Falk V, Seeburger J, Czesla M, Borger MA, Willige J, Kuntze T, et al. How does the use of polytetrafluoroethylene neochordae for posterior mitral valve prolapse (loop technique) compare with leaflet resection? A prospective randomized trial J Thorac Cardiovasc Surg. 2008;136:1206.

4. Tourmousoglou C, Lalos S, Dougenis D. Mitral valve repair of isolated posterior leaflet prolapse: resect or respect? Interact Cardiovasc Thorac Surg. 2014;19 $1027-35$.

5. Carpentier A. Cardiac valve surgery-the "French correction". J Thorac Cardiovasc Surg. 1983;86:323-37.

6. David TE. Replacement of chordae tendineae with expanded polytetrafluoroethylene sutures. J Card Surg. 1989;4:286-90.

7. Zussa C, Frater RW, Polesel E, Galloni M, Valfré C. Artificial mitral valve chordae: experimental and clinical experience. Ann Thorac Surg. 1990;50: 367-73.

8. Lange R, Guenther T, Noebauer C, Kiefer B, Eichinger W, Voss B, et al. Chordal replacement versus quadrangular resection for repair of isolated posterior mitral leaflet prolapse. Ann Thorac Surg. 2010;89:1163-70.

9. von Oppell UO, Mohr FW. Chordal replacement for both minimally invasive and conventional mitral valve surgery using premeasured Gore-Tex loops. Ann Thorac Surg. 2000;70:2166-8.

10. Tsang W, Freed BH, Lang RM. The role of 3-dimensional echocardiography in the diagnosis and management of mitral valve disease: myxomatous valve disease. Cardiol Clin. 2013;31:203-15.

11. Adams DH, Rosenhek R, Falk V. Degenerative mitral valve regurgitation: best practice revolution. Eur Heart J. 2010;31:1958-66.

12. Adams DH, Anyanwu AC, Rahmanian PB, Filsoufi F. Current concepts in mitral valve repair for degenerative disease. Heart Fail Rev. 2006;11: 241-57.

13. Duran CM, Pekar F. Techniques for ensuring the correct length of new mitral chords. J Heart Valve Dis. 2003;12:156-61.

14. Votta E, Le TB, Stevanella M, Fusini L, Caiani EG, Redaelli A, et al. Toward patient-specific simulations of cardiac valves: state-of-the-art and future directions. J Biomech. 2013;46:217-28.

15. Rim Y, Laing ST, McPherson DD, Kim H. Mitral valve repair using ePTFE sutures for ruptured mitral chordae tendineae: a computational simulation study Ann Biomed Eng. 2014;42:139-48.

16. Prot V, Haaverstad R, Skallerud B. Finite element analysis of the mitral apparatus: annulus shape effect and chordal force distribution. Biomech Model Mechanobiol. 2009;8:43-55

17. Sturla F, Onorati F, Votta E, Pechlivanidis K, Stevanella M, Milano AD, et al. Is it possible to assess the best mitral valve repair in the individual patient? Preliminary results of a finite element study from magnetic resonance imaging data. $J$ Thorac Cardiovasc Surg. 2014;148:1025-34.

18. Stevanella M, Maffessanti F, Conti C, Votta E, Arnoldi A, Lombardi M et al. Mitral valve patient-specific finite element modeling from cardiac MRI: application to an annuloplasty procedure. Cardiovasc Eng Tech. 2011;2:66-76.

19. Gillinov AM, Cosgrove DM, Lytle BW, Taylor PC, Stewart RW, McCarthy PM, et al. Reoperation for failure of mitral valve repair. J Thorac Cardiovasc Surg. 1997; 113:467-75.

20. el Asmar B, Perier P, Couetil JP, Carpentier A. Failures in reconstructive mitra valve surgery. J Med Liban. 1991;39:7-11. 
21. Dumont E, Gillinov AM, Blackstone EH, Sabik JF III, Svensson LG, Mihaljevic T, et al. Reoperation after mitral valve repair for degenerative disease. Ann Thorac Surg. 2007;84:444-50.

22. Maisano F, Cioni M, Seeburger J, Falk V, Mohr FW, Mack MJ, et al. Beatingheart implantation of adjustable length mitral valve chordae: acute and chronic experience in an animal model. Eur J Cardiothorac Surg. 2011;40:840-7.

23. Seeburger J, Rinaldi M, Nielsen SL, Salizzoni S, Lange R, Schoenburg M, et al. Off-pump transapical implantation of artificial neo-chordae to correct mitral regurgitation: the TACT Trial (Transapical Artificial Chordae Tendinae) proof of concept. J Am Coll Cardiol. 2014;63:914-9.

24. Jensen H, Jensen MO, Waziri F, Honge JL, Sloth E, Fenger-Gron M, et al. Transapical neochord implantation: is tension of artificial chordae tendineae dependent on the insertion site? J Thorac Cardiovasc Surg. 2014;148:138-43.
25. Rucinskas K, Janusauskas V, Zakarkaite D, Aidietiene S, Samalavicius R, Speziali G, et al. Off-pump transapical implantation of artificial chordae to correct mitral regurgitation: early results of a single-center experience. $J$ Thorac Cardiovasc Surg. 2014;147:95-9.

26. Roberts WC, Vowels TJ, Ko JM, Hebeler RF Jr. Gross and histological features of excised portions of posterior mitral leaflet in patients having operative repair of mitral valve prolapse and comments on the concept of missing (= ruptured) chordae tendineae. J Am Coll Cardiol. 2014;63: 1667-74.

Key Words: mitral valve prolapse, mitral valve repair, mitral neochordoplasty, suture length, finite element models

\title{
EDITORIAL COMMENTARY
}

\section{Tugging on heart strings}

\author{
Patrick M. McCarthy, MD
}

From the Division of Cardiac Surgery, Northwestern University, Chicago, Ill.

Disclosures: P.M.M. receives remuneration from Edwards Lifesciences (consultancy, royalties, intellectual property) and is the inventor of the Edwards MC3 Ring and dETlogix Ring and coinventor of the IMR Etlogix Ring. P.M.M. also receives remuneration from Abbott Vascular (consultancy). Author has nothing additional to disclose with regard to commercial support.

Received for publication Aug 4, 2015; accepted for publication Aug 8, 2015; available ahead of print Sept 1, 2015.

Address for reprints: Patrick M. McCarthy, MD, Executive Director of the Bluhm Cardiovascular Institute, Chief of the Cardiac Surgery Division, Heller-Sacks Professor of Surgery at the Northwestern University Feinberg School of Medicine, Northwestern University, Division of Cardiac Surgery, 201 E Huron St, Suite 11-140, Chicago, IL 60611-2908 (E-mail: pmccart@nmh.org).

J Thorac Cardiovasc Surg 2015;150:1312-3

0022-5223/\$36.00

Copyright $(\underset{ }{0} 2015$ by The American Association for Thoracic Surgery

http://dx.doi.org/10.1016/j.jtcvs.2015.08.013

The Achilles' heel of mitral valve repair has been the risk for immediate failure from uncorrected (residual) mitral regurgitation (MR) or the development of recurrent MR late after an apparently initially successful repair. The causes for recurrent MR are varied and include progression of native valve disease, endocarditis, ring dehiscence, scar tissue, and potentially leaving neochords too short or too long. ${ }^{1,2}$ The use of neochords seems to be increasing, judging by the literature (not easy to confirm from any national database as of now), and neochord techniques are varied. Many surgeons consider this approach an art. With the mean number of mitral operations per year per surgeon being much fewer than 10 per year in the United States, it is hard to perfect a technique that demands experience and precise execution of the art of surgery.

In this issue of the Journal, Sturla and colleagues ${ }^{4}$ from Italy report their identification of a more subtle potential source for failure. They posit that chord forces and leaflet

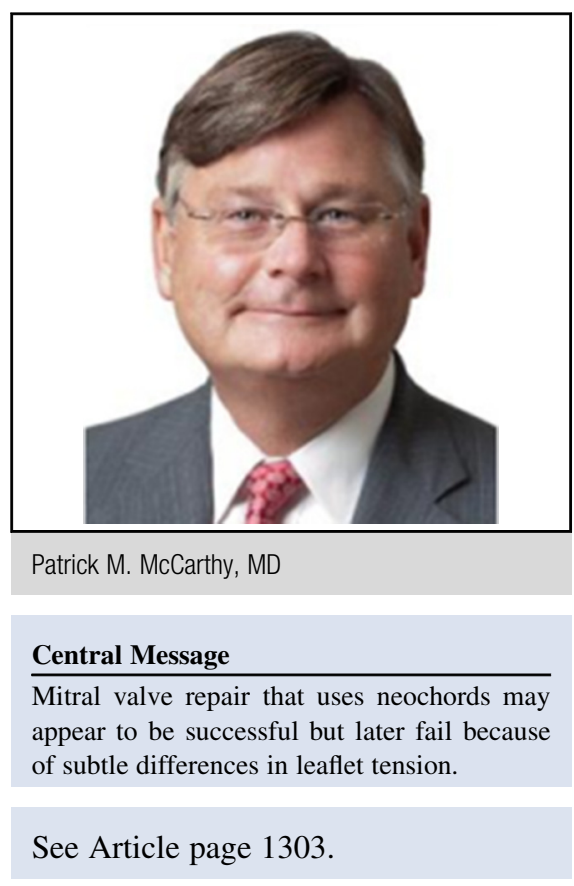

stresses may be clinically relevant even when apparently successful repairs without residual regurgitation have been achieved. From their data, these initially "subclinical" stresses appear to be more common when a single neochord is used or when multiple chords are used but create asymmetric configurations. Even with relatively small differences in chord length and symmetry $( \pm 2 \mathrm{~mm})$, patients with echocardiographically successful repairs and no MR have a less than "ideal" repair. The study is primarily based 


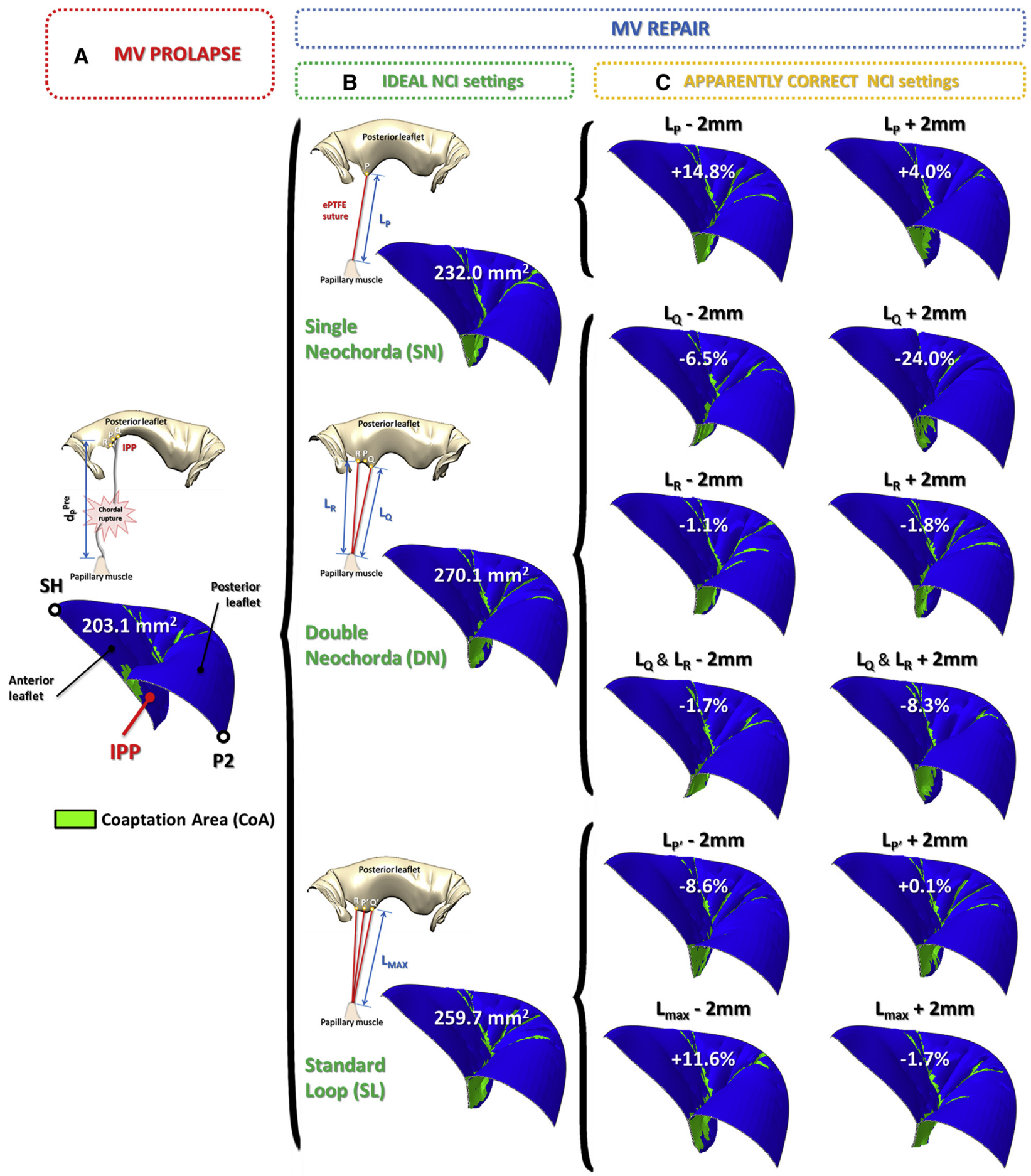

FIGURE E1. CoA measured at peak systole as the total extent of the elements in the posterior leaflet characterized by positive contact pressure with the anterior leaflet and reported in green color for each simulated configuration of patient 2, using a septo-lateral cut-view. A, CoA measured at peak systole under preoperative conditions (IPP). Percentage variation of CoA, with respect to the corresponding "ideal" (B) MV repair (SN, DN, and SL, respectively), is reported for each "apparently correct" configuration (C). All the reported "apparently correct" configurations are detailed in the section "Patient-Specific Mitral Valve Finite Element Modeling." $M V$, Mitral valve; $N C I$, neochordal implantation; $e P T F E$, expanded polytetrafluoroethylene; SH, saddle horn; IPP, isolated posterior leaflet; $P 2$, mid-point along the free margin of the posterior scallop; $D N$, double neochorda; $C o A$, coaptation area; $S L$, standard loop. 

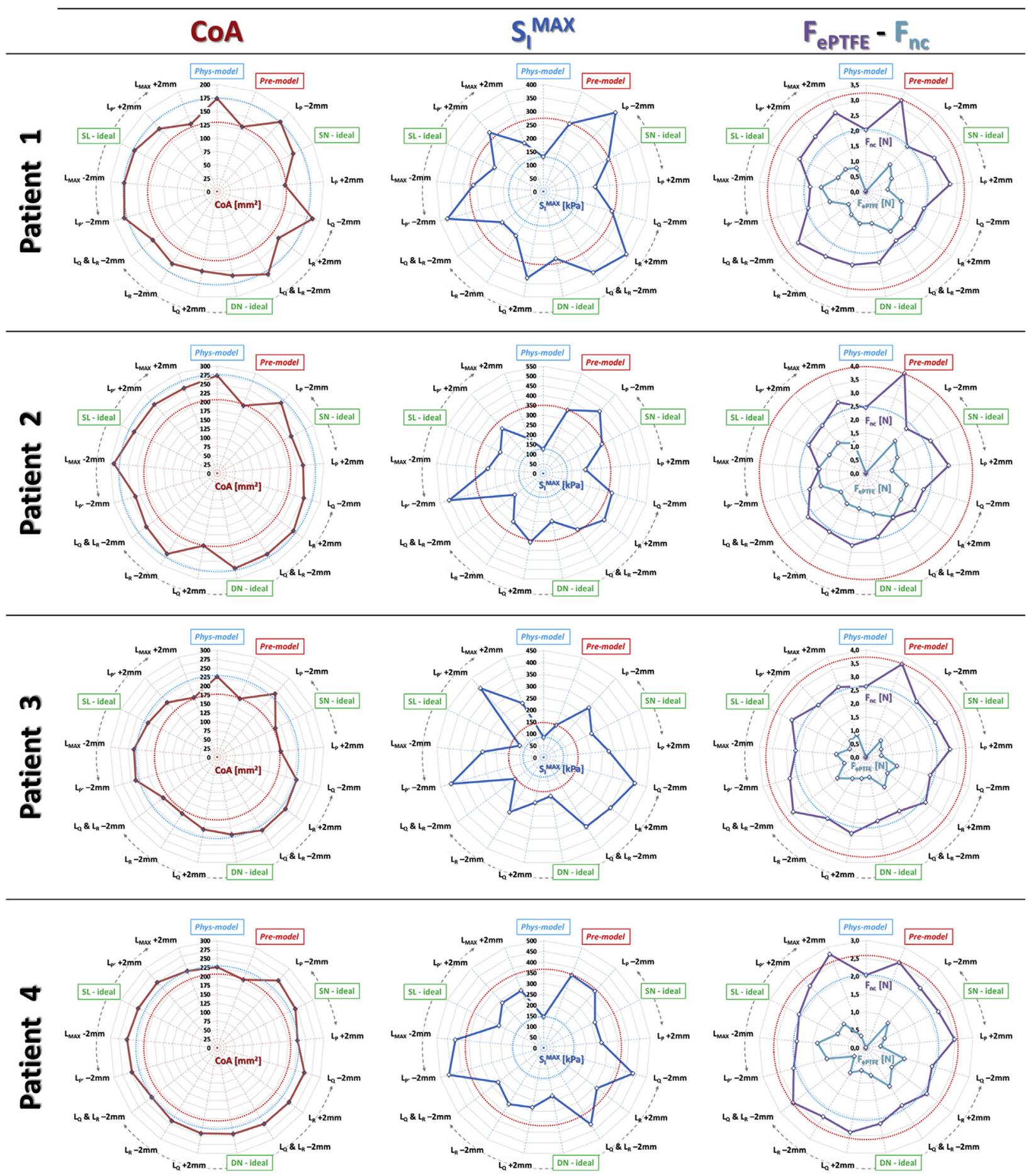

FIGURE E2. Radar charts of the computed MV biomechanical variables $\left(\mathrm{CoA}, \mathrm{S}_{\mathrm{I}}{ }^{\mathrm{MAX}}, \mathrm{F}_{\mathrm{ePTFE}}\right.$, and $\left.\mathrm{F}_{\mathrm{nc}}\right)$ at peak systole, under physiologic conditions (Phys-model, blue dotted circumference), in the preoperative IPP configuration (Pre-model, red dotted circumference), the "ideal" NCI simulations (SN, DN, and SL, respectively), and all the performed "apparently correct" NCI simulated configurations. All the reported "apparently correct" configurations are detailed in the section "Patient-Specific Mitral Valve Finite Element Modeling." CoA, Coaptation area; $S_{I}^{M A X}$, peak value of leaflet maximum principal stress; $F_{\text {ePTFE }}$, artificial chordae tension; $F_{n c}$, sum of tensions exerted by the native chordae tendineae; Phys-model, physiologic model; $S L$, standard loop; $S N$, single neochorda; $D N$, double neochorda. 
TABLE E1. Coaptation area and peak mechanical stress along the posterior free margin in Pre-models and after "ideal" and "apparently correct" neochordal tunings

\begin{tabular}{|c|c|c|c|c|}
\hline & Patient 1 & Patient 2 & Patient 3 & Patient 4 \\
\hline \multicolumn{5}{|l|}{$\mathrm{CoA}\left(\mathrm{mm}^{2}\right)$} \\
\hline IPP & 129.7 & 203.1 & 176.1 & 204.5 \\
\hline \multicolumn{5}{|l|}{$\mathrm{SN}$} \\
\hline Ideal & $159.0(+22.5)$ & $232.0(+14.2)$ & $182.3(+3.5)$ & $244.2(+19.4)$ \\
\hline $\mathrm{L}_{\mathrm{P}}+2 \mathrm{~mm}$ & $127.7(-1.6)$ & $241.3(+18.8)$ & $179.1(+1.7)$ & $225.7(+10.4)$ \\
\hline $\mathrm{L}_{\mathrm{P}}-2 \mathrm{~mm}$ & $176.1(+35.7)$ & $266.3(+31.1)$ & $240.6(+36.6)$ & $254.6(+24.5)$ \\
\hline \multicolumn{5}{|l|}{$\mathrm{DN}$} \\
\hline Ideal & $159.5(+23.0)$ & $270.1(+33.0)$ & $220.6(+13.5)$ & $244.9(+19.7)$ \\
\hline $\mathrm{L}_{\mathrm{Q}}+2 \mathrm{~mm}$ & $151.1(+16.4)$ & $205.4(+1.1)$ & $205.5(+16.7)$ & $243.3(+18.9)$ \\
\hline $\mathrm{L}_{\mathrm{Q}}-2 \mathrm{~mm}$ & $185.5(+43.0)$ & $252.4(+24.3)$ & $230.9(+31.1)$ & $254.1(+24.3)$ \\
\hline $\mathrm{L}_{\mathrm{R}}+2 \mathrm{~mm}$ & $158.4(+22.1)$ & $265.2(+30.6)$ & $185.8(+5.5)$ & $239.9(+17.3)$ \\
\hline $\mathrm{L}_{\mathrm{R}}-2 \mathrm{~mm}$ & $144.1(+11.1)$ & $267.2(+31.6)$ & $240.0(+36.3)$ & $251.7(+23.1)$ \\
\hline $\mathrm{L}_{\mathrm{Q}}$ and $\mathrm{L}_{\mathrm{R}}+2 \mathrm{~mm}$ & $150.0(+15.6)$ & $247.6(+21.9)$ & $188.5(+7.0)$ & $228.5(+11.7)$ \\
\hline $\mathrm{L}_{\mathrm{Q}}$ and $\mathrm{L}_{\mathrm{R}}-2 \mathrm{~mm}$ & $181.6(+40.0)$ & $265.6(+31.6)$ & $240.7(+36.7)$ & $249.9(+22.2)$ \\
\hline \multicolumn{5}{|l|}{ SL } \\
\hline Ideal & $171.6(+32.3)$ & $259.7(+27.8)$ & $215.7(+22.5)$ & $246.8(+20.7)$ \\
\hline $\mathrm{L}_{\mathrm{P}^{\prime}}+2 \mathrm{~mm}$ & $159.0(+22.6)$ & $260.1(+28.0)$ & $207.1(+17.6)$ & $247.6(+21.1)$ \\
\hline $\mathrm{L}_{\mathrm{P}^{\prime}}-2 \mathrm{~mm}$ & $179.9(+38.7)$ & $237.5(+16.9)$ & $236.5(+34.3)$ & $247.9(+21.2)$ \\
\hline $\mathrm{L}_{\mathrm{MAX}}+2 \mathrm{~mm}$ & $135.2(+4.2)$ & $255.2(+25.7)$ & $179.1(+1.7)$ & $230.7(+12.8)$ \\
\hline $\mathrm{L}_{\mathrm{MAX}}-2 \mathrm{~mm}$ & $174.1(+34.2)$ & $289.9(+42.7)$ & $233.9(+32.8)$ & $253.1(+23.8)$ \\
\hline \multicolumn{5}{|l|}{$\mathrm{S}_{\mathrm{I}}^{\mathrm{MAX}}(\mathrm{kPa})$} \\
\hline IPP & 272.0 & 349.1 & 145.6 & 364.1 \\
\hline \multicolumn{5}{|l|}{ SN } \\
\hline Ideal & $270.8(-0.4)$ & $337.8(-3.2)$ & $225.8(+55.1)$ & $267.4(-26.6)$ \\
\hline $\mathrm{L}_{\mathrm{P}}+2 \mathrm{~mm}$ & $194.8(-28.4)$ & $218.1(-37.5)$ & $276.0(+89.6)$ & $271.3(-25.5)$ \\
\hline $\mathrm{L}_{\mathrm{P}}-2 \mathrm{~mm}$ & $399.3(+46.8)$ & $430.6(+23.4)$ & $282.7(+94.1)$ & $356.9(-2.0)$ \\
\hline \multicolumn{5}{|l|}{$\mathrm{DN}$} \\
\hline Ideal & $254.4(-6.5)$ & $248.7(-28.8)$ & $165.1(+13.4)$ & $227.2(-37.6)$ \\
\hline $\mathrm{L}_{\mathrm{Q}}+2 \mathrm{~mm}$ & $327.8(-20.5)$ & $357.4(+2.4)$ & $192.6(+32.3)$ & $282.3(-22.5)$ \\
\hline $\mathrm{L}_{\mathrm{Q}}-2 \mathrm{~mm}$ & $265.9(-2.2)$ & $368.3(+5.5)$ & $397.9(+173.2)$ & $433.6(+19.1)$ \\
\hline $\mathrm{L}_{\mathrm{R}}+2 \mathrm{~mm}$ & $193.9(-28.7)$ & $289.6(-17.0)$ & $271.1(+86.2)$ & $307.6(-15.5)$ \\
\hline $\mathrm{L}_{\mathrm{R}}-2 \mathrm{~mm}$ & $389.0(+43.0)$ & $394.7(+13.1)$ & $352.1(+141.1)$ & $311.7(-14.4)$ \\
\hline $\mathrm{L}_{\mathrm{Q}}$ and $\mathrm{L}_{\mathrm{R}}+2 \mathrm{~mm}$ & $190.7(-29.9)$ & $181.6(-48.0)$ & $149.0(+2.3)$ & $265.0(-27.2)$ \\
\hline $\mathrm{L}_{\mathrm{Q}}$ and $\mathrm{L}_{\mathrm{R}}-2 \mathrm{~mm}$ & $355.5(+30.7)$ & $336.4(-3.6)$ & $341.5(+134.5)$ & $419.0(+15.1)$ \\
\hline \multicolumn{5}{|l|}{ SL } \\
\hline Ideal & $202.7(-25.5)$ & $245.8(-29.6)$ & $111.4(-23.5)$ & $231.6(-36.4)$ \\
\hline $\mathrm{L}_{\mathrm{P}^{\prime}}+2 \mathrm{~mm}$ & $298.3(-25.5)$ & $311.5(-10.8)$ & $392.8(+169.7)$ & $284.1(-22.0)$ \\
\hline $\mathrm{L}_{\mathrm{P}^{\prime}}-2 \mathrm{~mm}$ & $371.1(+36.7)$ & $501.1(+43.6)$ & $403.1(+176.8)$ & $457.2(+25.6)$ \\
\hline $\mathrm{L}_{\mathrm{MAX}}+2 \mathrm{~mm}$ & $194.2(-28.6)$ & $190.6(-45.4)$ & $243.9(+67.5)$ & $286.3(-21.4)$ \\
\hline $\mathrm{L}_{\mathrm{MAX}}-2 \mathrm{~mm}$ & $261.5(-3.9)$ & $284.1(-18.6)$ & $256.7(+76.2)$ & $412.8(+13.4)$ \\
\hline
\end{tabular}

All the reported "apparently correct" configurations are detailed in the section "Patient-Specific Mitral Valve Finite Element Modeling." Percentage variations with respect to IPP models are reported in parentheses for each postoperative simulation. CoA, Coaptation area; IPP, preoperative simulation reproducing isolated posterior prolapse; $S N$, single neochorda; $D N$, double neochorda; $S L$, standard loop; $S_{I}^{M A X}$, peak mechanical stress along the posterior free-margin. 
TABLE E2. Tension exerted by expanded polytetrafluoroethylene neochordae and native residual chordae in the prolapsing region in preoperative models (isolated posterior prolapse) after ideal (single neochorda, double neochorda, and standard loop) and apparently optimal neochordal tunings, respectively

\begin{tabular}{|c|c|c|c|c|}
\hline & Patient 1 & Patient 2 & Patient 3 & Patient 4 \\
\hline \multicolumn{5}{|l|}{$\mathrm{F}_{\mathrm{ePTFE}}(\mathrm{N})$} \\
\hline IPP & - & - & - & - \\
\hline \multicolumn{5}{|l|}{$\mathrm{SN}$} \\
\hline Ideal & $0.94(100)$ & $1.31(100)$ & $0.65(100)$ & $0.59(100)$ \\
\hline $\mathrm{L}_{\mathrm{P}}+2 \mathrm{~mm}$ & $0.72(100)$ & $0.99(100)$ & $0.59(100)$ & $0.42(100)$ \\
\hline $\mathrm{L}_{\mathrm{P}}-2 \mathrm{~mm}$ & $1.19(100)$ & $1.62(100)$ & $0.83(100)$ & $0.92(100)$ \\
\hline \multicolumn{5}{|l|}{$\mathrm{DN}$} \\
\hline Ideal & $1.06(45,55)$ & $1.54(59,41)$ & $0.76(58,42)$ & $0.79(63,37)$ \\
\hline $\mathrm{L}_{\mathrm{Q}}+2 \mathrm{~mm}$ & $1.07(21,79)$ & $1.34(31,69)$ & $0.81(48,52)$ & $0.65(8,92)$ \\
\hline $\mathrm{L}_{\mathrm{Q}}-2 \mathrm{~mm}$ & $1.21(77,23)$ & $1.59(85,15)$ & $1.21(83,17)$ & $1.12(100,0)$ \\
\hline $\mathrm{L}_{\mathrm{R}}+2 \mathrm{~mm}$ & $0.89(90,10)$ & $1.33(91,9)$ & $0.94(70,30)$ & $0.83(97,3)$ \\
\hline $\mathrm{L}_{\mathrm{R}}-2 \mathrm{~mm}$ & $1.44(16,84)$ & $1.64(27,73)$ & $1.02(19,81)$ & $0.91(9,91)$ \\
\hline $\mathrm{L}_{\mathrm{Q}}$ and $\mathrm{L}_{\mathrm{R}}+2 \mathrm{~mm}$ & $0.71(55,45)$ & $1.16(70,30)$ & $1.32(66,34)$ & $0.40(29,71)$ \\
\hline $\mathrm{L}_{\mathrm{Q}}$ and $\mathrm{L}_{\mathrm{R}}-2 \mathrm{~mm}$ & $1.53(34,62)$ & $1.92(50,50)$ & $1.32(63,38)$ & $1.27(78,22)$ \\
\hline \multicolumn{5}{|l|}{ SL } \\
\hline Ideal & $1.00(13,48,39)$ & $1.51(29,30,41)$ & $0.67(45,44,11)$ & $0.87(51,24,25)$ \\
\hline $\mathrm{L}_{\mathrm{P}^{\prime}}+2 \mathrm{~mm}$ & $0.98(23,0,77)$ & $1.52(34,0,66)$ & $0.82(65,0,35)$ & $0.90(60,0,40)$ \\
\hline $\mathrm{L}_{\mathrm{P}^{\prime}}-2 \mathrm{~mm}$ & $1.21(0,100,0)$ & $1.74(0,100,0)$ & $0.83(4,87,9)$ & $1.13(0,100,0)$ \\
\hline $\mathrm{L}_{\mathrm{MAX}}+2 \mathrm{~mm}$ & $0.82(39,33,28)$ & $1.20(31,33,36)$ & $0.90(28,59,13)$ & $0.35(6,62,32)$ \\
\hline $\mathrm{L}_{\mathrm{MAX}}-2 \mathrm{~mm}$ & $1.46(20,30,50)$ & $1.79(26,29,45)$ & $1.10(53,23,24)$ & $1.36(64,11,25)$ \\
\hline \multicolumn{5}{|l|}{$\mathrm{F}_{\mathrm{nc}}[\mathrm{N}]$} \\
\hline IPP & 3.21 & 3.99 & 3.72 & 2.56 \\
\hline \multicolumn{5}{|l|}{ SN } \\
\hline Ideal & $2.50(-22.2)$ & $2.70(-32.4)$ & $2.89(-22.2)$ & $2.25(-11.8)$ \\
\hline $\mathrm{L}_{\mathrm{P}}+2 \mathrm{~mm}$ & $2.76(-14.0)$ & $3.10(-22.2)$ & $3.16(-15.2)$ & $2.48(-2.9)$ \\
\hline $\mathrm{L}_{\mathrm{P}}-2 \mathrm{~mm}$ & $2.00(-37.6)$ & $2.25(-43.6)$ & $2.81(-24.5)$ & $2.25(-12.1)$ \\
\hline \multicolumn{5}{|l|}{$\mathrm{DN}$} \\
\hline Ideal & $2.34(-27.2)$ & $2.41(-39.6)$ & $2.42(-34.9)$ & $2.16(-15.6)$ \\
\hline $\mathrm{L}_{\mathrm{Q}}+2 \mathrm{~mm}$ & $2.43(-24.4)$ & $2.73(-31.5)$ & $2.90(-22.0)$ & $2.41(-5.8)$ \\
\hline $\mathrm{L}_{\mathrm{Q}}-2 \mathrm{~mm}$ & $1.97(-38.6)$ & $2.24(-43.9)$ & $2.50(-32.9)$ & $1.92(-24.9)$ \\
\hline $\mathrm{L}_{\mathrm{R}}+2 \mathrm{~mm}$ & $2.48(-22.8)$ & $2.56(-35.7)$ & $2.70(-27.5)$ & $2.27(-11.2)$ \\
\hline $\mathrm{L}_{\mathrm{R}}-2 \mathrm{~mm}$ & $1.97(-38.8)$ & $2.26(-43.4)$ & $2.79(-24.9)$ & $2.13(-16.5)$ \\
\hline $\mathrm{L}_{\mathrm{Q}}$ and $\mathrm{L}_{\mathrm{R}}+2 \mathrm{~mm}$ & $2.76(-14.0)$ & $2.69(-32.5)$ & $3.39(-8.9)$ & $2.55(+0.0)$ \\
\hline $\mathrm{L}_{\mathrm{Q}}$ and $\mathrm{L}_{\mathrm{R}}-2 \mathrm{~mm}$ & $1.87(-41.7)$ & $1.94(-51.5)$ & $2.37(-36.2)$ & $1.90(-25.5)$ \\
\hline \multicolumn{5}{|l|}{ SL } \\
\hline Ideal & $2.41(-24.9)$ & $2.38(-40.4)$ & $3.09(-17.0)$ & $2.09(-18.3)$ \\
\hline $\mathrm{L}_{\mathrm{P}^{\prime}}+2 \mathrm{~mm}$ & $2.44(-24.1)$ & $2.41(-39.7)$ & $2.63(-29.3)$ & $2.33(-8.9)$ \\
\hline $\mathrm{L}_{\mathrm{P}^{\prime}}-2 \mathrm{~mm}$ & $1.95(-39.3)$ & $2.17(-45.6)$ & $2.94(-20.8)$ & $2.10(-17.8)$ \\
\hline $\mathrm{L}_{\mathrm{MAX}}+2 \mathrm{~mm}$ & $2.77(-13.9)$ & $2.84(-28.9)$ & $2.80(-24.6)$ & $2.80(+9.6)$ \\
\hline $\mathrm{L}_{\mathrm{MAX}}-2 \mathrm{~mm}$ & $1.82(-43.2)$ & $1.74(-56.4)$ & $2.63(-29.3)$ & $1.94(-24.0)$ \\
\hline
\end{tabular}

All the reported "apparently correct" configurations are detailed in the section "Patient-Specific Mitral Valve Finite Element Modeling." Values are reported as absolute numbers and percentages in parentheses. Percentage variations with respect to IPP models are reported in parentheses for Fnc; percentage integer redistribution from $0 \%$ to $100 \%$ of tension on each ePTFE suture is reported in parentheses for $\mathrm{F}_{\mathrm{ePTFE}}$, according to the specific setup of each neochordal configuration. $F_{\text {ePTFE }}$, Neochordal tension and its percentage redistribution between artificial sutures; $I P P$, preoperative simulation; $S N$, single neochorda; $D N$, double neochorda; $S L$, standard loop; $F_{n c}$, native chordal tension in the prolapsing region. 